\title{
Performance of Sthree Shakthi Groups (SSGs) in Dharwad and Tumkur district of Karnataka
}

See end of the paper for authors' affiliations J.M. SARASWATHI

Department of Family Resource Management, Siddaganga Polytechnic College, Batawadi, TUMKUR (KARNATAKA) INDIA Email : saru.shan36@yahoo.com
ABSTRACT : The study was conducted in Dharwad and Tumkur districts during the yes 2013-14 to study the performance of Sthree Shakthi Goups in selected districts of Karnataka i.e. Dharwad and Tumkur. This paper highlights the performance of Sthree Shakthi Groups (SSGs) in Karnataka and it was found that, the mean differences between Dharwad and Tumkur for almost all the indicators were very narrow even with varied sample size. Thus, SSGs from both the selected were found to be at par with respect to performance but, Z-values of the table indicated that differ significantly for micro enterprise development and for total at five per cent level.

KEY WORDS: Self-help groups, Sthree shakthi groups, Performance indicators, Department of women and child development

- HOW TO CITE THIS PAPER : Saraswathi, J.M. and Sumangala, P.R. (2015). Performance of Sthree Shakthi Groups (SSGs) in Dharwad and Tumkur district of Karnataka. Asian J. Home Sci., 10 (1) : 185-189. 